(2) Open Access Full Text Article

\title{
Comparison of Outcomes in Patients with
}

\section{Obesity Between Two Administration Routes of Omeprazole After Laparoscopic Sleeve Gastrectomy: An Open-Label Randomized Clinical Trial}

\author{
Qin $\operatorname{Tan} \mathbb{D}^{1, *}$ \\ Yanding Gao ${ }^{1, *}$ \\ Pin Zhang ${ }^{2}$ \\ Yan $\mathrm{Huo}^{3}$ \\ Yihan $\mathrm{Lu}^{4,5}$ \\ Weifeng Huang' \\ 'Department of Critical Care, The Sixth \\ People's Hospital, Shanghai Jiao Tong \\ University, Shanghai, People's Republic of \\ China; ${ }^{2}$ Department of General Surgery, \\ The Sixth People's Hospital, Shanghai Jiao \\ Tong University, Shanghai, People's \\ Republic of China; ${ }^{3}$ Department of \\ Pharmacy, The Sixth People's Hospital, \\ Shanghai Jiao Tong University, Shanghai, \\ People's Republic of China; ${ }^{4}$ Department \\ of Epidemiology, School of Public Health, \\ Fudan University, Shanghai, People's \\ Republic of China; ${ }^{5}$ National Health \\ Commission Key Laboratory of Health \\ Technology Assessment, Fudan \\ University, Shanghai, People's Republic of \\ China \\ *These authors contributed equally to \\ this work
}

Correspondence: Weifeng Huang Department of Critical Care, The Sixth People's Hospital, Shanghai Jiao Tong University, No. 600 Yi Shan Road, Shanghai, 200233, People's Republic of China

Email breeze-huang@hotmail.com
This article was published in the following Dove Press journal: Drug Design, Development and Therapy

Background: The effect of different administration routes of omeprazole remains unclear on the recovery in patients with obesity after laparoscopic sleeve gastrectomy (LSG).

Methods: We designed a randomized clinical trial enrolling 120 patients with a BMI $\geq 32.5$ $\mathrm{kg} / \mathrm{m}^{2}$ after LSG. They were randomized into two groups to be administered with omeprazole by rapid intravenous injection (group A) or by continuous micropump infusion (group B). The plasma concentration of omeprazole was monitored upon initiating administration. Change in intragastric $\mathrm{pH}$ and gastrointestinal symptoms during follow-up served as indicators for therapeutic evaluation.

Results: Patients in the two groups showed no difference in the AUC curves $(\mathrm{P}=0.25)$, but group A had significantly higher peak concentration $(\mathrm{P}<0.001)$, and shorter time to reach peak concentration after administration $(\mathrm{P}<0.001)$, compared to group $\mathrm{B}$. Before and after the administration of omeprazole, the average change in intragastric $\mathrm{pH}$ was much lower in group $\mathrm{A}(0.031 \pm 0.61)$ than in group $\mathrm{B}(0.48 \pm 0.74)(\mathrm{P}=0.004)$. The incidence of gastrointestinal symptoms was similar between the two groups $(\mathrm{P}=0.85)$; however, the average duration of remaining symptoms was longer in group A (3.97 months; 95\% CI, 2.90-5.04) than in group $\mathrm{B}$ (2.82 months; 95\% CI, 2.01-3.63) ( $\mathrm{P}=0.04)$.

Conclusion: Continuous micropump infusion of omeprazole may improve the outcomes in patients with obesity after LSG.

Trial registration: China Clinical Trial Registration Center (ChiCTR), ChiCTR-IPR-17013365. Registered 13 November 2017. http://www.chictr.org.cn/showproj.aspx?proj=22892.

Keywords: obesity, laparoscopic sleeve gastrectomy, omeprazole, gastrointestinal symptoms

\section{Background}

Obesity has become a global public concern that is closely related to the occurrence and development of non-communicable diseases, such as hypertension, type 2 diabetes mellitus, dyslipidaemia, cardiovascular events and even a variety of malignant tumours. ${ }^{1}$ Globally from 1980 through 2016, the estimated number of overweight and obese people has increased from 857 million to 2.1 billion According to the World Health Organization. Approximately, 671 million people have a BMI $\geq 30 \mathrm{~kg} / \mathrm{m}^{2}$. Chinese individuals account for one-tenth of these people, which means one of every hundred 
in China suffers from obesity. ${ }^{3}$ For most patients, the effects of non-surgical treatment remain minimal and are reversible. The only validated treatment with long-term effects is weight-loss surgery, which can also reduce the levels of blood glucose and blood lipid and reduce the incidence of various obesity-related complications. ${ }^{4}$

Bariatric surgery is recommended as the new guidelines for patients with a BMI above $32.5 \mathrm{~kg} / \mathrm{m}^{2}$ in China. ${ }^{5}$ Laparoscopic sleeve gastrectomy (LSG) is effective for obesity and globally become popular, owing to a few severe complications and substantial weight loss. ${ }^{6}$ However, some undesired gastrointestinal symptoms, such as pantothenic acid, nausea, early satiety, hoarseness, dysphagia, sore throat, chest pain, and epigastric pain, may effect quite a few postoperative patients. ${ }^{7}$ After removing most of the stomach fundus and body, the volume of the remnant stomach got much smaller than before, which increased the gastric pressure and decreased the gastric compliance decreased. ${ }^{8}$ Expectantly, Proton pump inhibitor (PPI) is one of the best choices of the drug to relieve these symptoms by reducing gastric acid secretion and protecting the barrier of gastric wall. ${ }^{9}$

Omeprazole, the first generation of PPI, is commonly used for the treatment of peptic ulcers, stress ulcers, reflux oesophagitis, gastrinoma and other digestive system acid secretion diseases. ${ }^{9}$ Omeprazole is lipid-soluble, weak basic and easy to deteriorate under light, heat, acid and oxidant conditions. Previous studies reported that compared to intravenous injection when the omeprazole is delivered via micropump, it could reduce the bleeding of peptic ulcers, which may be related to micropump infusion making the plasma concentration of omeprazole more stable. ${ }^{10,11}$ Studies in healthy people showed that the distribution of omeprazole in vivo conforms to the two compartments open model, and its clinical efficacy is positively correlated with areas under the curve (AUC). ${ }^{12}$ However, to the best of our knowledge, there is no study which focused on the pharmacokinetics of omeprazole in obese humans.

In order to address this, we enrolled patients with obesity who underwent LSG and then received omeprazole either via rapid intravenous injection (Group A) or continuous micropump infusion (Group B). We then compared outcomes, including plasma omeprazole concentration, intragastric $\mathrm{pH}$, and gastrointestinal symptoms, between these groups. Our study aimed to determine the pharmacokinetics of omeprazole in obese people, and to assess whether micropump infusion could result in improved outcomes in this population following LSG.

\section{Methods}

\section{Trial Design}

We designed an open-label randomized clinical trial comparing the outcomes of two omeprazole administration routes after LSG. We prospectively enrolled the patients who met the inclusion criteria $\left(\mathrm{BMI} \geq 32.5 \mathrm{~kg} / \mathrm{m}^{2}\right)^{5}$ and underwent LSG from November 2017 through October 2019 in The Sixth People's Hospital, Shanghai Jiao Tong University. The exclusion criteria were as follows: 1) being allergic to omeprazole or other benzimidazole drugs; or 2) not being capable of maintaining postoperative diet or lifestyle change. This trial was registered in the China Clinical Trial Registration Center (ChiCTR-IPR-17013365). In addition, patient data were collected by one researcher blinded to the trial, mainly including age, gender, BMI and comorbidities.

\section{Justification of Sample Size}

This trial is aimed to prospectively compare compared the outcomes, including plasma concentration of omeprazole, intragastric $\mathrm{pH}$, and gastrointestinal symptoms, between the two groups. The sample size is calculated using the software PASS 11 (NCSS, LLC. Kaysville, Utah, USA) with twosample $T$-test. We utilized the change in the intragastric $\mathrm{pH}$ value to estimate the sample size. It was previously documented that the mean change was 2.58 between the $\mathrm{pH}$ values before and after the administration of omeprazole by intravenous injection in Chinese patients with peptic ulcer. ${ }^{13}$ In another study, the mean change in Chinese newborn with stress ulcer administered with omeprazole by intravenous injection and micropump infusion was 1.6 and 2.84 (2.84 was larger than 1.6 by 1.775 times), respectively. ${ }^{14}$ However, there was limited data available in the patients with obesity. To obtain a maximum sample size for appropriate statistical power, we estimated the change in the intragastric $\mathrm{pH}$ value to be 2.58 (intravenous injection) and $4.58(2.58 * 1.775=4.58$; micropump infusion), with a standard deviation $(\sigma)$ of 5 , in the patients with obesity. In addition, $\alpha$ and $\beta$ were given values of 0.05 and 0.2 , respectively, as usual. Thus, the sample size was determined to be 200 with 100 in each group.

In the trial, we found that it was difficult to collect the sample of succus gastricus, as it had been reduced by about $90 \%$ after $\mathrm{LSG}^{15}$ and would be further reduced about $80 \%$ after omeprazole administration. ${ }^{16}$ To measure the intragastric $\mathrm{pH}$ value accurately, we injected $20 \mathrm{~mL}$ saline to the patients' stomach through the nasogastric tube and drew out the succus gastricus after 5 minutes in all the patients. The $\mathrm{pH}$ value was measured in the specimens after centrifuged. In addition, it was 
not easy to enroll more patients in the study. Moreover, in the late December, 2019, the epidemic of COVID-19 occurred in China, which impeded the patients with obesity admitting to the hospital. Accordingly, we had to estimate the statistical power on the current sample size (60 in each group), which was determined to be 0.95 , based on a change in the intragastric $\mathrm{pH}$ of $0.031 \pm 0.61$ (intravenous injection) and $0.48 \pm 0.74$ (micropump infusion), which was presented in the Results. Thus, we considered terminating the trial, which was finally approved by the Ethics Committee of the Shanghai Sixth People's Hospital.

\section{Randomization and Administration of Omeprazole}

We designed a two-year study to enroll more patients with a $\mathrm{BMI} \geq 32.5 \mathrm{~kg} / \mathrm{m}^{2}$ after $\mathrm{LSG}$, as this population in China remains limited. A total of 135 patients with obesity were assessed for eligibility (Figure 1); of them, 125 were eligible and then randomized into two groups, group A (rapid intravenous injection) and group B (continuous micropump infusion) to take omeprazole after $\mathrm{LSG}$, in a 1:1 ratio. One researcher performed a simple randomization using computer-generated random numbers, and another researcher blinded to the trial implemented the randomization. Administration of omeprazole was conducted open-label in this unblended trial.
Participating patients in group A received intravenous injection of omeprazole (AstraZeneca Ltd., China State Food and Drug Administration Approval Number: H20030945) at a dose of $40 \mathrm{mg}$ over 30 minutes, whereas those in group B received continuous micropump infusion of omeprazole at the same dose lasting for 6 hours. During the next three days, each participant in the trial received different administration routes by their groups twice a day.

\section{Measurement of Short-Term Outcome}

Once omeprazole was administrated, blood samples from the opposite dorsalis pedis artery were taken from the patients at the points of time at $0.25 \mathrm{~h}, 0.5 \mathrm{~h}, 1 \mathrm{~h}, 2 \mathrm{~h}, 4$ $\mathrm{h}, 6 \mathrm{~h}, 8 \mathrm{~h}, 12 \mathrm{~h}$ and $18 \mathrm{~h}$, respectively, by a same experienced nurse blinded to the study data, to examine the plasma concentration of omeprazole. The areas under the curve (AUCs) of the plasma concentration were then calculated as described elsewhere. ${ }^{7}$ Time to reach peak concentration after administration (Tmax) and peak concentration (Cmax) were determined accordingly.

Meanwhile, patients' gastric acid was obtained through gastric tube to exam $\mathrm{pH}$ values before and 24 hours after administration of omeprazole, which was measured by FiveEasy Plus (Mettler Toledo, German).

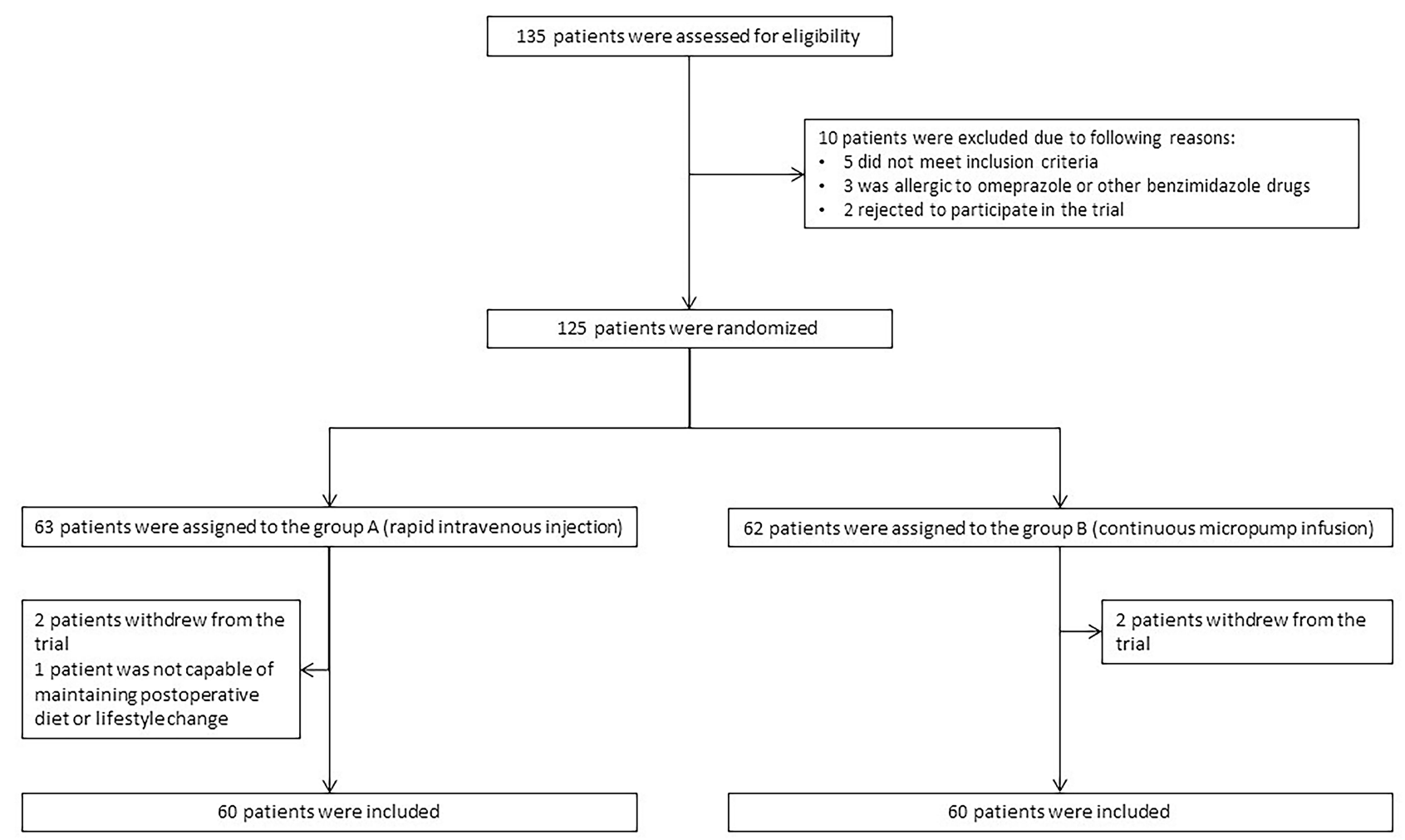

Figure I The flowchart of the inclusion of the patients in the trial. 


\section{Follow-Up and Measurement of Long-Term Outcome}

Follow-up was conducted at 1, 3, 6 and 12 months after the administration of omeprazole. The lost to follow-up was recorded and average duration of follow-up were calculated. Gastrointestinal symptoms, including heartburn, acid reflux, dysphagia and vomiting, were defined as primary outcome in this trial. The incidence density of gastrointestinal symptoms and duration of remaining symptoms was determined and compared in two groups.

\section{Statistical Analysis}

Baseline characteristics, plasma concentration of omeprazole, and change in intragastric $\mathrm{pH}$ values between the two groups were compared by using one-way ANOVA, Chisquare test, Fisher's exact test, and nonparametric test where applicable. Omeprazole pharmacokinetics was inferred based on time-dependent plasma concentration by using DAS 2.0 (Mathematical Pharmacology Professional Committee of China). Then, the AUC of the plasma concentration of omeprazole was calculated by the trapezoidal rule. Age and BMI were explored as covariates associated with the AUC by analysis of covariance.

In the follow-up, we observed that once the patients reported non-occurrence of gastrointestinal symptoms in one visit, they did not report any symptom in the following visits. Thus, we utilized Kaplan-Meier survival analysis and defined non-occurrence of symptoms as an "event". The log-rank method was employed to compare the cumulative probability of the symptoms between the two groups. All analyses were performed using SPSS (SPSS Inc., Chicago, IL, USA). A $P$ value less than 0.5 was considered statistically significant.

\section{Results}

\section{Short-Term Outcomes After Omeprazole}

\section{Administration}

A total of 125 patients were initially included in the study. However, 5 of them withdrew from the trial at baseline. Baseline characteristics are listed in Table 1. There is no significant difference in demographics and comorbidity status between the two groups.

The plasma concentration of omeprazole varied between the two groups. The AUC value of the plasma concentration was similar between group A $(6577.23 \pm 4539.25)$ and group $\mathrm{B}(5616.65 \pm 4541.62)(P=0.25)$. There was also no significant interaction between administration route and age $(P=0.11)$ or BMI $(P=0.85)$ in regard to the AUC. Furthermore, Tmax was significantly different between group A $(2.10 \pm 4.51)$ and group B $(4.58 \pm 2.41)(P<0.001)$. Similarly, Cmax differed between group A $(2157.35 \pm 931.34)$ and group B $(967.75 \pm$ 1259.17) $(P<0.001)$.

In addition, change in the intragastric $\mathrm{pH}$ values was determined by assessing the $\mathrm{pH}$ before and after the administration of omeprazole in 42 patients in group $\mathrm{A}$ and 41 patients in group $\mathrm{B}$. The average change in $\mathrm{pH}$ was much lower in group $\mathrm{A}(0.031 \pm 0.61)$ than in group B $(0.48 \pm 0.74)(P=0.004)$ (Table 2$)$. To make the difference more visible, we made a box-plot according to the data (Figure 2).

Table I Baseline Characteristics

\begin{tabular}{|c|c|c|c|}
\hline & $\begin{array}{c}\text { Group A (Rapid Intravenous } \\
\text { Injection) } \\
(n=60)\end{array}$ & 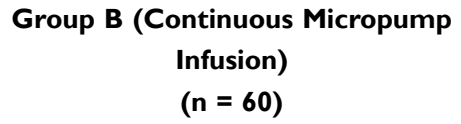 & $P$ value \\
\hline Age (year), mean $\pm S D$ & $34.95 \pm 9.94$ & $32.38 \pm 8.93$ & 0.14 \\
\hline Sex (female, \%) & $47(78.3)$ & $40(66.7)$ & 0.15 \\
\hline BMI, mean \pm SD & $41.19 \pm 7.29$ & $39.65 \pm 6.18$ & 0.21 \\
\hline \multicolumn{4}{|l|}{ Comorbidity (\%) } \\
\hline Cardiovascular disease & $\mathrm{I}(\mathrm{I} .7)$ & $2(3.3)$ & 1.0 \\
\hline Hypertension & $14(23.3)$ & $12(20.0)$ & 0.66 \\
\hline Diabetes & $27(45.0)$ & $26(43.3)$ & 0.85 \\
\hline $\begin{array}{l}\text { Obstructive sleep apnea } \\
\text { syndrome }\end{array}$ & I (I.7) & $4(6.7)$ & 0.36 \\
\hline Fatty Liver & $20(33.3)$ & $20(33.3)$ & 1.0 \\
\hline Hyperlipidemia & $3(5.0)$ & $\mathrm{I}(\mathrm{I} .7)$ & 0.62 \\
\hline
\end{tabular}


Table 2 Change in the Intragastric $\mathrm{pH}$ Value Before and After Administration of Omeprazole

\begin{tabular}{|l|c|c|c|c|}
\hline \multirow{2}{*}{} & \multicolumn{2}{|c|}{ Group A (Rapid Intravenous Injection) } & \multicolumn{2}{c|}{ Group B (Continuous Micropump Infusion) } \\
\cline { 2 - 5 } & No. Patients & $\begin{array}{c}\text { Average Change } \\
\text { (Mean } \pm \text { SD) }\end{array}$ & No. Patients & $\begin{array}{c}\text { Average Change } \\
\text { (Mean } \pm \text { SD) }\end{array}$ \\
\hline Increase & 20 & $0.55 \pm 0.43$ & 29 & $0.82 \pm 0.59$ \\
Decrease & 22 & $-0.44 \pm 0.28$ & 12 & $-0.36 \pm 0.24$ \\
\hline
\end{tabular}

\section{Long-Term Outcomes in the Follow-Up}

In this study, the occurrence of gastrointestinal symptoms was recorded at 1, 3, 6 and 12 months postoperation. All patients were visited at 1 month and 3 months. In the following visits, 5 patients in group A (1 at 6-month and 4 at 12-month) and 4 patients in group B (1 at 6-month and 3 at 12-month) were lost. The average duration of followup was $11.45 \pm 1.87$ months in group A and $11.55 \pm 1.73$ months in group $\mathrm{B}$, with no significant difference $(P=0.76)$.

In two groups, gastrointestinal symptoms were recorded in 26 patients in group A and 25 patients in group $\mathrm{B}$ during the follow-up $(P=0.85)$. Then, due to the lost to follow-up, the incidence density was determined to be 0.45 per person-year in group A and 0.43 per personyear in group $\mathrm{B}$. The duration of remaining symptoms was estimated to be 3.97 months ( $95 \% \mathrm{CI}, 2.90-5.04$ ) in group $\mathrm{A}$ and 2.82 months (95\% CI, 2.01-3.63) in group B, suggesting that the patients in group B were likely to have significantly faster recovery than those in group A $(P=0.04$; Figure 3$)$.

\section{Discussion}

Tradition medical treatment has a very limited impact on obesity, with short-term weight loss often rebounding within 5 years. $^{3}$ Surgery, particularly LSG, has become the only standardized way to manage obesity. However, this often results in uncomfortable gastrointestinal symptoms, ${ }^{17}$ with previously reported incidences ranging from $2.1 \%$ to $21.0 \% .{ }^{18}$ In our study, the incidence of these symptoms was higher, occurring in 51 of $120(42.5 \%)$ of people during 1 year of follow-up.

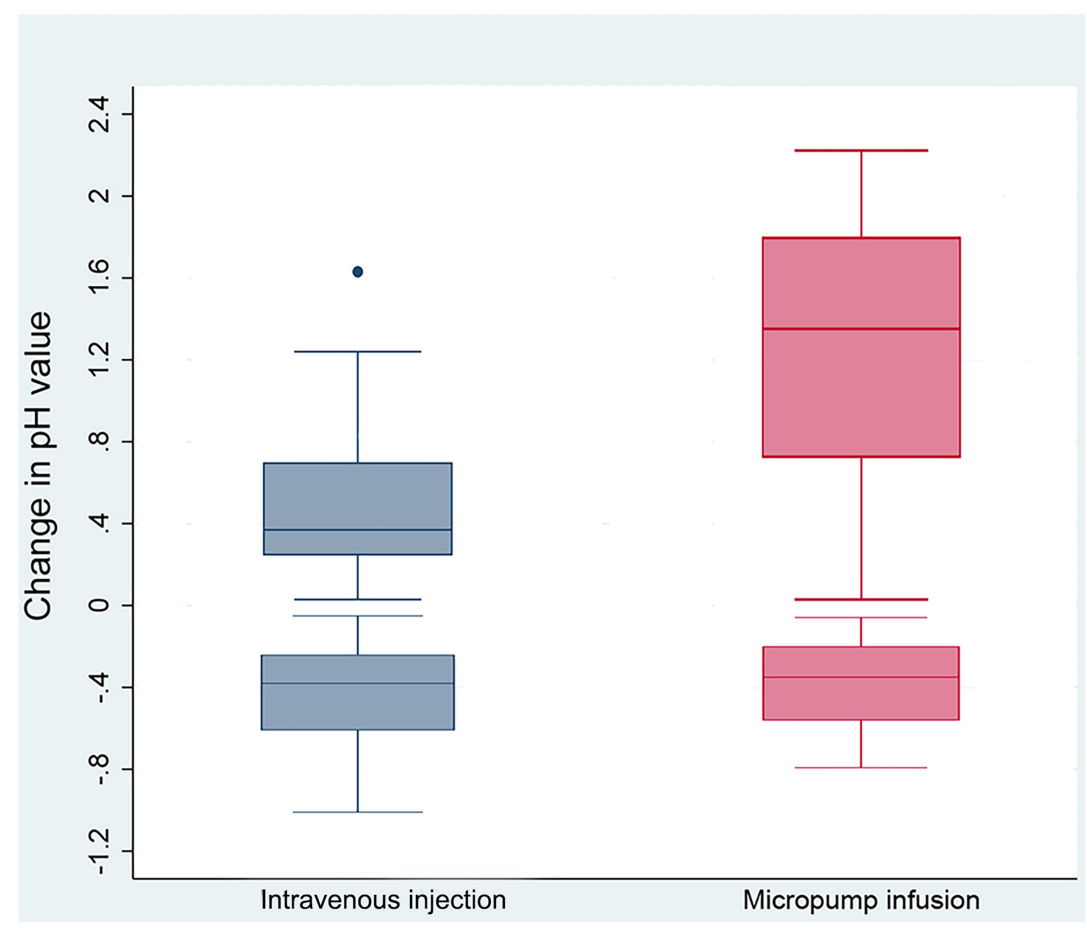

Figure 2 Change in the intragastric $\mathrm{pH}$ value before and after administration of omeprazole. 


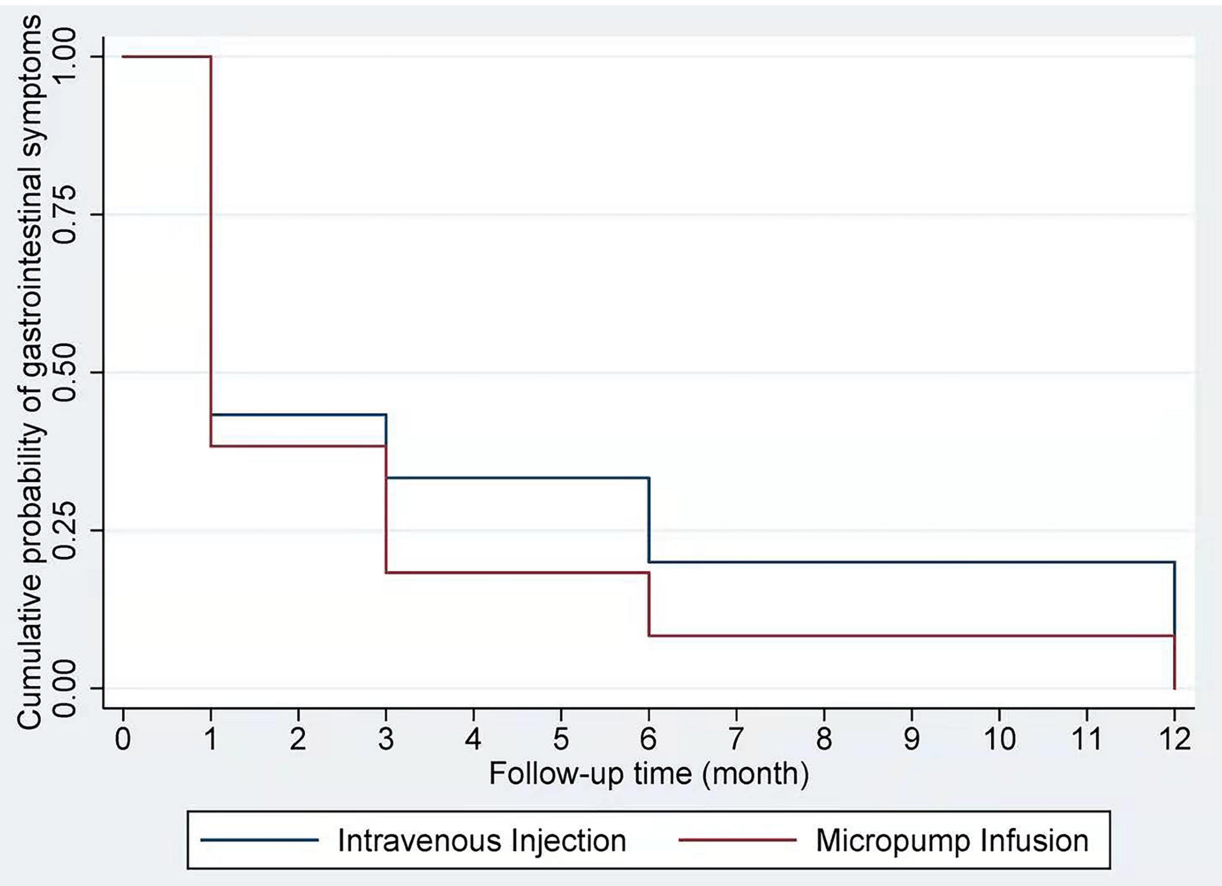

Figure 3 Cumulative probability of gastrointestinal symptoms.

Tradition medical treatment has a very limited impact on obesity, with short-term weight loss often rebounding within 5 years. ${ }^{3}$ Surgery, particularly LSG, has become the only standardized way to manage obesity. However, this often results in uncomfortable gastrointestinal symptoms, ${ }^{17}$ with previously reported incidences ranging from $2.1 \%$ to $21.0 \% .{ }^{18}$ In our study, the incidence of these symptoms was higher, occurring in 51 of $120(42.5 \%)$ of people during 1 year of follow-up.

As a first-generation PPI, omeprazole can inhibit $\mathrm{H}^{+} \mathrm{K}^{+}$ adenosine triphosphatase (ATPase) by activating the high-acid environment of the tubules in gastric parietal cells. ${ }^{19,20}$ Therefore, the transport of $\mathrm{H}^{+}$from parietal cells into the cell cavity is blocked, preventing gastric acid secretion. ${ }^{21}$ Previous studies in healthy people showed that the distribution of omeprazole confirms the two-compartment open model, and its clinical efficacy is positively correlated with the AUC, ${ }^{22}$ however, until now, no pharmacokinetic data were available for omeprazole use in obese people.

Our study demonstrated that there was no significant difference in the AUC between obese people who received omeprazole via rapid intravenous injection and those who received the drug via continuous micropump infusion $(p=$ 0.25). However, there was a significantly higher peak concentration of omeprazole and a shorter time to peak concentration following administration via injection compared with infusion. This aligns with previous research demonstrating that continuous micropump drug delivery sustains the equilibrium between the drug intake and elimination rates. ${ }^{23,24}$ The conflicting results in peak concentration in our study may result from the interaction of fatty tissue and drug distribution. ${ }^{10}$ In addition, the approved dosage of omeprazole is currently the same for those with a BMI classed as "normal" and those classed as "obese"; omeprazole may therefore be less effective in those with a higher BMI owing to a lower drug concentration to weight ratio, however, it has not yet been investigated whether a higher dosage may be beneficial for this group. This may help to explain the lack of significance in the difference between the AUC for the two administration routes in our study; further studies focusing on the effect of different dosages delivered via various administration routes could clarify this.

Compared with those who received omeprazole via injection, there was a significantly greater increase in intragastric $\mathrm{pH}$ and shorter duration of reported gastrointestinal symptoms in those who received the drug via micropump infusion, suggesting that this route may significantly improve outcomes in obese patients following LSG. Previous studies have shown that the effect of continuous, low-dose micropump infusion of omeprazole 
for the treatment of neonatal stress ulcers was significant, and could improve clinical symptoms, which aligns with our results. ${ }^{25,26}$ Although rapid intravenous injection is simple, convenient, and commonly used, it often results in an unstable plasma concentration; ${ }^{14}$ intravenous infusion using a micropump could better sustain the equilibrium between drug intake and elimination rates, which may more effectively alleviate gastrointestinal symptoms.

There are several limitations to this study. First, this was a single-center study with a small sample size based on the number of patients with obesity in this center at the time, which was limited. Second, the majority of the patients in this study was women, which may have resulted in a gender bias and a limited applicability of our results to men. This reflects the general trend in China that women are more likely to agree to undergo weight-loss surgery than men; research from northern China in 2018 reported that women accounted for $74.7 \%$ of all weight-loss surgery patients. ${ }^{27}$ Third, we measured a point value for intragastric $\mathrm{pH}$, rather than a continuous $24 \mathrm{~h}$ value, which might be an unreliable measurement. We chose to measure a point value because a dynamic $\mathrm{pH}$ monitoring machine is invasive; though it has been widely used for evaluating $\mathrm{pH}$ levels in studies of various antacids, ${ }^{28}$ people with obesity are very susceptible to secondary injury after LSG, including through the use of invasive monitoring equipment such as this.

\section{Conclusions}

Obese patients who received omeprazole via continuous micropump infusion had a greater increase in intragastric $\mathrm{pH}$ after LSG compared with those who received the drug via rapid intravenous injection. The duration of gastrointestinal symptoms was also significantly shorter with micropump infusion than with intravenous injection, indicating that continuous micropump infusion may enable faster recovery from surgery. Therefore, continuous micropump infusion of omeprazole may improve postoperative management of obese people who undergo LSG.

\section{Abbreviations}

AUC, Area under the curve; BMI, Body mass index; Cmax, Peak concentration; LSG, Laparoscopic sleeve gastrectomy; PPI, Proton pump inhibitor; Tmax, Time to reach peak concentration after administration.

\section{Data Sharing Statement}

The datasets generated during and/or analyzed during the current study are not publicly available due to the privacy policy but are available from the corresponding author on reasonable request.

\section{Ethics Approval}

All procedures performed in studies involving human participants were in accordance with the Ethics Committee of the Shanghai Sixth People's Hospital (approval No. 2017-132). Written informed consent was obtained from all individual participants included in the study. Our trial was conducted in accordance with the Declaration of Helsinki.

\section{Acknowledgments}

The study adheres to CONSORT guidelines.

\section{Author Contributions}

$\mathrm{WH}$ and $\mathrm{YL}$ conceived and designed the study. YG, PZ, $\mathrm{YH}$, and $\mathrm{WH}$ conducted the clinical trial. YG and QT performed the analysis and prepared the manuscript. YL and WH critically revised the manuscript. All authors made substantial contributions to conception and design, acquisition of data, or analysis and interpretation of data; took part in drafting the article or revising it critically for important intellectual content; agreed to submit to the current journal; gave final approval of the version to be published; and agree to be accountable for all aspects of the work.

\section{Funding}

This study did not receive any specific grant from funding agencies in the public, commercial, or not-for-profit sectors.

\section{Disclosure}

The authors declare that they have no competing interests.

\section{References}

1. Cecchini M, Sassi F, Lauer JA, et al. Tackling of unhealthy diets, physical inactivity, and obesity: health effects and cost-effectiveness. Lancet. 2010;376(9754):1775-1784. doi:10.1016/S0140-6736(10) 61514-0

2. World obesity federation about obesity. Available from: https://www. worldobesity.org/about/about-obesity. Accessed March 27, 2021.

3. Ng M, Fleming T, Robinson M, et al. Global, regional, and national prevalence of overweight and obesity in children and adults during 1980-2013: a systematic analysis for the Global Burden of Disease Study 2013. Lancet. 2014;384(9945):766-781. doi:10.1016/S01406736(14)60460-8 
4. Rebibo L, Marechal V, De Lameth I, et al. Compliance with a multidisciplinary team meeting's decision prior to bariatric surgery protects against major postoperative complications. Surg Obes Relat Dis. 2017;13(9):1537-1543. doi:10.1016/j.soard.2017.05.026

5. Chinese Society for Metabolic \& Bariatric Surgery. The guidelines for surgical treatment of obesity and T2D in China. Chin J Pract Surg. 2019;39(4):301-306.

6. Helmio M, Victorzon M, Ovaska J, et al. Comparison of short-term outcome of laparoscopic sleeve gastrectomy and gastric bypass in the treatment of morbid obesity: a prospective randomized controlled multicenter SLEEVEPASS study with 6-month follow-up. Scand J Surg. 2014;103(3):175-181. doi:10.1177/1457496913509984

7. Himpens J, Dapri G, Cadiere GB. A prospective randomized study between laparoscopic gastric banding and laparoscopic isolated sleeve gastrectomy: results after 1 and 3 years. Obes Surg. 2006;16 (11):1450-1456. doi:10.1381/096089206778869933

8. Gibson SC, Le Page PA, Taylor CJ. Laparoscopic sleeve gastrectomy: review of 500 cases in single surgeon Australian practice. $A N Z$ $J$ Surg. 2015;85(9):673-677. doi:10.1111/ans.12483

9. Furuta T, Shirai N, Sugimoto M, Ohashi K, Ishizaki T. Pharmacogenomics of proton pump inhibitors. Pharmacogenomics. 2004;5(2):181-202. doi:10.1517/phgs.5.2.181.27483

10. Wei M, Xiao Y. Study of stability of omeprazole in micro-pump by continuous administration. China Pharm. 2005;16:1884-1885.

11. Richter JE, Kahrilas PJ, Johanson J, et al. Efficacy and safety of esomeprazole compared with omeprazole in GERD patients with erosive esophagitis: a randomized controlled trial. Am J Gastroenterol. 2001;96(3):656-665. doi:10.1111/j.1572-0241.2001.03600.x

12. Hanley MJ, Abernethy DR, Greenblatt DJ. Effect of obesity on the pharmacokinetics of drugs in humans. Clin Pharmacokinet. 2010;49 (2):71-87. doi:10.2165/11318100-000000000-00000

13. He X, Li Y, Yang X, et al. Effects of endoscopic hemostasis in combination with different dose of omeprazole effect in the treatment of elderly peptic ulcer bleeding. Mod Dig Intervention. 2019;24 (2):183-185.

14. Chen J. Clinical efficacy and safety of continuous intravenous infusion of low dosage omeprazole for the treatment of neonatal stress ulcer. Chin J Clin Pharmacol. 2015;31(18):1812-1814.

15. Csendes A, Braghetto I. Changes in the anatomy and physiology of the distal esophagus and stomach after sleeve gastrectomy. $J$ Obes Weight Loss Ther. 2016;6:297. doi:10.4172/2165-7904.1000297

16. Shin JM, Sachs G. Pharmacology of proton pump inhibitors. Curr Gastroenterol Rep. 2008;10(6):528-534. doi:10.1007/s11894-0080098-4
17. Nilsson M, Johnsen R, Ye W, et al. Obesity and estrogen as risk factors for gastroesophageal reflux symptoms. JAMA. 2003;290 (1):66-72. doi:10.1001/jama.290.1.66

18. Himpens J, Dobbeleir J, Peeters G. Long-term results of laparoscopic sleeve gastrectomy for obesity. Ann Surg. 2010;252(2):319-324. doi:10.1097/SLA.0b013e3181e90b31

19. Stenard F, Iannelli A. Laparoscopic sleeve gastrectomy and gastroesophageal reflux. World J Gastroenterol. 2015;21(36):10348-10357. doi:10.3748/wjg.v21.i36.10348

20. Miner P Jr., Katz PO, Chen Y, Sostek M. Gastric acid control with esomeprazole, lansoprazole, omeprazole, pantoprazole, and rabeprazole: a five-way crossover study. Am J Gastroenterol. 2003;98 (12):2616-2620. doi:10.1111/j.1572-0241.2003.08783.x

21. Saccar CL. The pharmacology of esomeprazole and its role in gastric acid related diseases. Expert Opin Drug Metab Toxicol. 2009;5 (9):1113-1124. doi:10.1517/17425250903124363

22. McKeage K, Blick SKA, Croxtall JD, et al. Esomeprazole: a review of its use in the management of gastric acid-related diseases in adults. Drugs. 2008;68(11):1571-1607. doi:10.2165/00003495-20086811000009

23. Zahn JD, Deshmukh A, Pisano AP, Liepmann D. Continuous on-chip micropumping for microneedle enhanced drug delivery. Biomed Microdevices. 2004;6(3):183-190. doi:10.1023/B: BMMD.0000042047.83433.96

24. Peterson KA, Thomas KL, Hilden K, et al. Comparison of esomeprazole to aerosolized, swallowed fluticasone for eosinophilic esophagitis. Dig Dis Sci. 2010;55(5):1313-1319. doi:10.1007/ s10620-009-0859-4

25. Mo S. Clinical efficacy and safety evaluation of continuous low-dose micropump infusion of omeprazole in the treatment of stress ulcer in neonates. Chin Foreign Med Res. 2018;16(17):28-30.

26. Duan W, Tan Y, Peng Z. Efficacy of continuous intravenous infusion of low-dose omeprazole in the treatment of neonatal stress ulcer. $J$ Ped Pharm. 2013;19(1):12-14.

27. Liu Y, Li M, Zhang S, et al. North China bariatric \& metabolic surgery clinical database registry report (2018). Chinese J Pract Surg. 2019;39:54-59.

28. Baldwin CM, Keam SJ. Rabeprazole: a review of its use in the management of gastric acid-related diseases in adults. Drugs. 2009;69:1373-1401. doi:10.2165/00003495-200969100-00007

\section{Publish your work in this journal}

Drug Design, Development and Therapy is an international, peerreviewed open-access journal that spans the spectrum of drug design and development through to clinical applications. Clinical outcomes, patient safety, and programs for the development and effective, safe, and sustained use of medicines are a feature of the journal, which has also been accepted for indexing on PubMed Central. The manuscript management system is completely online and includes a very quick and fair peer-review system, which is all easy to use. Visit http://www. dovepress.com/testimonials.php to read real quotes from published authors. 